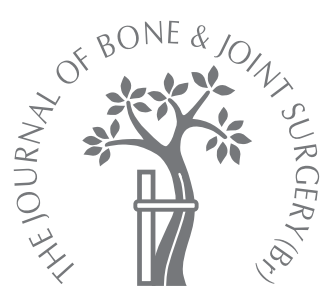

R. K. Nath,

A. B. Lyons, S. E. Melcher, M. Paizi

From the Texas Nerve and Paralysis Institute, Houston, USA

R. K. Nath, MD, Plastic and Reconstructive Surgeon

A. B. Lyons, BSc, Research Assistant

S. E. Melcher, BA, Research Scientist

M. Paizi, DSc, Research Scientist

Texas Nerve and Paralysis Institute, 2201 W. Holcombe Boulevard, Houston, Texas 77030, USA.

Correspondence should be sent to Dr R. K. Nath; e-mail: nath@drnathmedical.com

(C)2007 British Editorial Society of Bone and Joint Surgery doi:10.1302/0301-620X.89B12. $18757 \$ 2.00$

$J$ Bone Joint Surg $[\mathrm{Br}]$ 2007;89-B:1638-44.

Received 9 October 2006:

Accepted after revision 4 June 2007

\title{
Surgical correction of the medial rotation contracture in obstetric brachial plexus palsy
}

\begin{abstract}
The medial rotation contracture caused by weak external rotation secondary to obstetric brachial plexus injury leads to deformation of the bones of the shoulder. Scapular hypoplasia, elevation and rotation deformity are accompanied by progressive dislocation of the humeral head. Between February and August 2005, 44 children underwent a new surgical procedure called the 'triangle tilt' operation to correct this bony shoulder deformity. Surgical levelling of the distal acromioclavicular triangle combined with tightening of the posterior glenohumeral capsule (capsulorrhaphy) improved shoulder function and corrected the glenohumeral axis in these patients. The posture of the arm at rest was improved and active external rotation increased by a mean of $53^{\circ}\left(0^{\circ}\right.$ to $\left.115^{\circ}\right)$ in the 40 children who were followed up for more than one year.
\end{abstract}

There was a mean improvement of 4.9 points (1.7 to 8.3) of the Mallet shoulder function score after surgical correction of the bony deformity.

In the USA, obstetric brachial plexus injury has an incidence of 0.38 to 1.56 per 1000 live births. ${ }^{1}$ Perinatal risk factors include an increased weight-for-gestation age, previous deliveries resulting in brachial plexus injury, multiparous pregnancies, prolonged labour and breech, assisted or difficult delivery. ${ }^{1}$ The upper trunk (C5-6) is most commonly injured, with no injury to the middle or lower trunk. Less often, the entire plexus including T1 may be involved. Lesions may be caused by simple stretch or varying degrees of rupture and/or avulsion. Considerable recovery of strength can be expected in patients who recover biceps function by the third month. ${ }^{2}$ However, only infants who recover antigravity biceps strength in the first four to six weeks of life will have symmetry of their shoulder girdles on longterm examination. ${ }^{3}$ Shoulder problems which initially present as weakness of the deltoid and external shoulder rotators are the most consistent functional and anatomical derangements which result from a C5 injury. ${ }^{4}$

The asymmetrical injury presents clinically with contractures of the internal rotators and adductors of the shoulder since the innervation to these muscles is less affected and growth of the limb is influenced by the muscle imbalance around the shoulder. Bony deformities develop with time as a result of the contractures and asymmetrical muscle action on the developing bony elements of the shoulder. The major bony deformity is an elevation and protraction of the scapula termed the SHEAR (scapular hypoplasia, elevation and rotation) deformity (Fig. 1). Secondary effects are medial rotation and posterior and inferior subluxation of the humerus in the glenoid fossa. ${ }^{4}$ Other deformities include flattening of the glenoid fossa and hooking of the acromion process which impinges on the humeral head.

The bone and muscle abnormalities result in a classical clinical presentation of the arm at rest with apparent shortening of the humerus and deep anterior and posterior axillary folds as a result of the contractures of the underlying latissimus dorsi, teres major and pectoralis. The internally-rotated arm is abducted several degrees and the elbow consequently flexes. ${ }^{5}$ Typically, the dorsum of the hand is visible anteriorly. During active movement of the arm, abduction is diminished because of the axillary and pectoral contractures. External rotation of the arm and shoulder is limited because of impingement of the distal acromioclavicular triangle against the humeral head, the anatomical basis for the medial rotation contracture. Additionally, there are varying degrees of elbow flaring on flexion of the elbow (the 'bugler's position') and difficulty in placing the hands on the nape of the neck. The muscle and bone deformities are a direct result of the initial nerve injury, occurring during a period of rapid growth. 


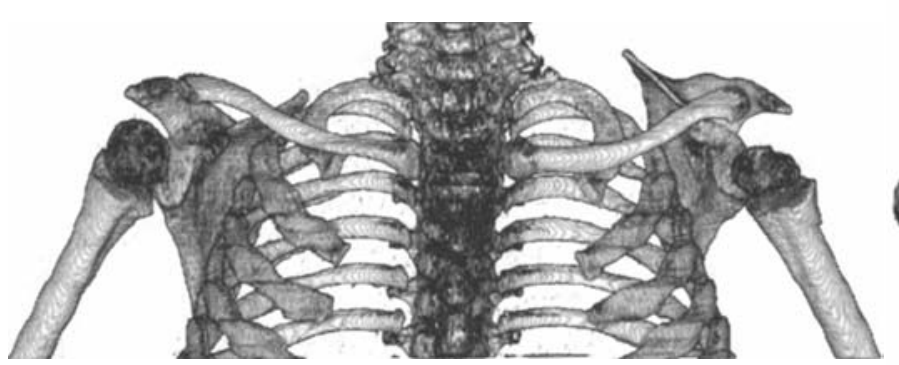

Fig. 1a

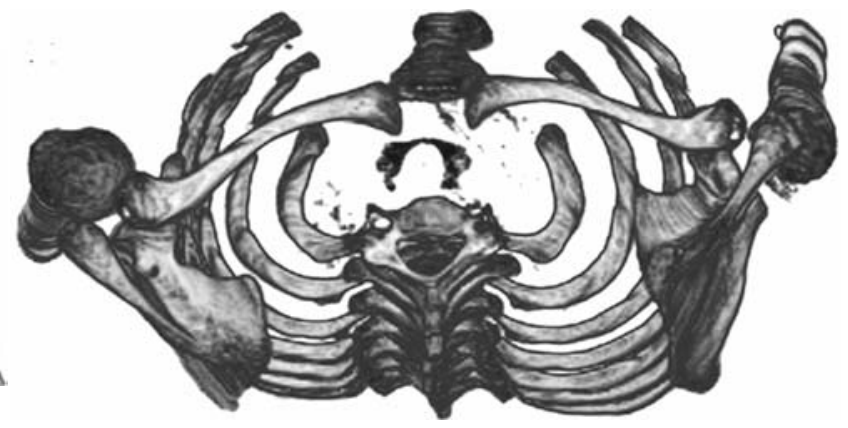

Fig. 1b

Three-dimensional CT views of the scapular hypoplasia, elevation and rotation deformity showing a) an anterior trunk view of an elevated scapula and b) a superior trunk outlet view with forward elevation of the scapula.

The abduction deficit can be improved by soft-tissue procedures including contracture releases, tendon transfers and axillary nerve decompression. ${ }^{6-9}$ However, the medial rotation contracture because of the SHEAR deformity is more difficult to correct.

The traditional approach has been the use of external rotation osteotomy of the humerus to improve the position of the hand and forearm. While this may help the resting position and active external rotation at the shoulder, it does not correct the primary scapular elevation and rotation. Recurrence of the medial rotation deformity is common after humeral osteotomy and related to the presence of an unrecognised SHEAR deformity with impingement of the distal acromioclavicular triangle against the humeral head. Posterior glenohumeral capsulodesis, anterior glenohumeral capsular release and humeral osteotomy either above or below the deltoid insertion do not address this deformity and a different approach has been suggested. ${ }^{10}$

Scapular elevation and rotation result in a multidirectional and complex series of bony movements which cause medial rotation of the humeral head and shaft with the classical presentation previously described. It is probably the lateral movement of the scapula which results in the humeral rotation and the medial rotation contracture is thus primarily a bony deformity. Therefore a bony surgical approach is indicated to correct the deformity. The surgical procedure which we now describe was conceived as a response to the abnormal bony development seen in the SHEAR deformity. The strategy was to release the distal acromioclavicular triangle from the medial spine of the scapula and the medial clavicle by osteotomies of the clavicle and neck of the acromion. This allows the distal triangle to tilt back into its neutral position, in essence levelling the triangle. The operation is therefore called the 'triangle tilt' procedure.

The release and tilting of the acromioclavicular plane back to neutral appears to relieve the impingement of the acromioclavicular triangle on the humeral head and allows the latter to be repositioned passively into a neutral posi- tion in the glenoid fossa. This improves the chance of satisfactory long-term function. In this study, we have retrospectively reviewed the results of the triangle tilt procedure in a group of children with obstetric brachial plexus injury.

\section{Patients and Methods}

Between February and August 2005, 44 patients with obstetric brachial plexus injury and persistent internal rotation deformity underwent the triangle tilt procedure. Four of these were lost to follow-up because they were unreachable with the contact information provided at the time of surgery. The remaining 40 were followed up clinically for at least 12 months and had sufficient data for analysis. None had undergone previous bony surgery. There were 13 boys and 27 girls with a mean age of 6.4 years (2.2 to 10.3 ). Primary nerve surgery had been undertaken in infancy in ten $(25 \%)$. Previous posterior glenohumeral capsulorrhaphy to reposition the humeral head had been attempted in ten $(25 \%)$, but had failed in all. All 40 patients had previously undergone muscle contracture release, tendon transfers and decompression of the axillary nerve in the quadrangular space. ${ }^{6-9}$ This improved their abduction to a mean of $160^{\circ}$ $\left(90^{\circ}\right.$ to $\left.180^{\circ}\right)$, but the medial rotation posture at rest had persisted and had not responded to physiotherapy and splinting.

Physical examination revealed the presence of a SHEAR deformity which was confirmed by three-dimensional (3D)CT whenever possible (Fig. 1). All patients were assessed pre- and post-operatively by video recordings of standardised movements using a modified Mallet classification to assess active shoulder abduction. ${ }^{11}$ In order to define their functional disability more precisely, the angle of the handto-mouth movement (bugler's sign) and the angle of forearm supination secondary to external rotation were recorded.

All evaluations and measurements were performed by trained scientists (MP, SEM) independent of the surgeon and principal author. 


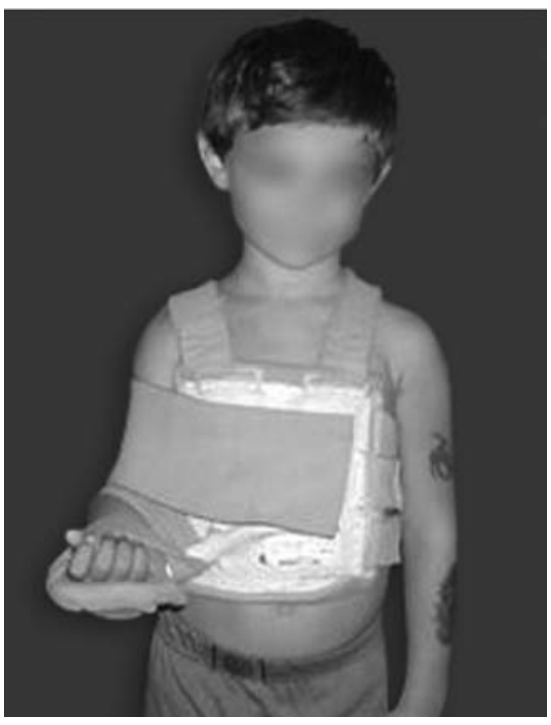

Fig. 2

Photograph showing the splint for immobilisation of the shoulder after triangle tilt surgery.

Glenohumeral deformity and subluxation were graded pre-operatively on axial CT or MRI according to the method of Waters, Smith and Jaramillo ${ }^{12}$ and by 3D-CT to determine the severity of the underlying SHEAR deformity. ${ }^{13}$ On a transverse CT image at the midglenoid level, a scapular line was constructed which connected the medial margin of the scapula to the middle of the glenoid fossa. The glenoscapular angle (glenoid version) was measured according to Friedman, Hawthorne and Genez ${ }^{14}$ as the angle between the scapular line (connecting the medial margin of the scapula to the middle of the glenoid) and the line connecting the base of the anterior labrum and posterior labrum. By definition, $90^{\circ}$ are subtracted from the posteromedial quadrant angle to define the glenoscapular angle. The same scapular line is used to determine the degree of subluxation of the humeral head. The greatest diameter of the head was measured, as was the distance of the scapular line to the anterior portion of the head. The percentage of subluxation was calculated as the ratio of these distances multiplied by 100 .

There was a high degree of correlation between the increasing grade of SHEAR deformity and the degree of subluxation $(r=0.62)$. The body of the scapula tended to be hypoplastic and osteopenic as were the humeral head and shaft.

Operative technique. The triangle tilt procedure consists of osteotomy of the clavicle at the junction of the middle and outer thirds, osteotomy of the acromion at its junction with the spine of the scapula, ostectomy of the superomedial angle of the scapula and splinting of the limb in adduction, $5^{\circ}$ of external rotation and full forearm supination (Fig. 2).
Splinting was maintained for six weeks, after which time the splint was worn only at night for an additional three to six months. Minor elements of the procedure included bone grafting of the site of the acromial osteotomy and semirigid fixation of the clavicular osteotomy to prevent nonunion. Posterior glenohumeral capsulorraphy was performed in patients with instability of the shoulder diagnosed by preoperative CT or positional MRI.

All the operations were performed by the same surgeon (RKN), who has experience of over 4000 patients with obstetric brachial plexus injury over a ten-year period.

Statistical analysis. All tests of significance of the continuous variables pre-operatively and at the most recent clinical follow-up were conducted using the paired Student $t$-test in Microsoft Excel 2003 (Microsoft, Redmond, Washington).

\section{Results}

Nonunion of the clavicular osteotomy occurred in two patients early in the series and was treated by wire fixation. This complication led to the introduction of semi-rigid fixation of the clavicular fragments by titanium pins (Smith \& Nephew Donjoy, Carlsbad, California) connected by an absorbable suture. The titanium pins were subcutaneous and tied together with absorbable sutures.

At the final follow-up examination at a mean of 15.1 months (12 to 20), the mean Mallet score had improved from a pre-operative score of 13.6 points (9 to 19) to 18.6 points ( 14 to $22 ; t$-test $\mathrm{p}<0.000)$. The mean active global range of shoulder movement was not significantly affected. Hand-to-mouth movements had improved. The bugler's sign significantly decreased from a mean of $110^{\circ}\left(60^{\circ}\right.$ to $\left.160^{\circ}\right)$ pre-operatively to $36^{\circ}\left(0^{\circ}\right.$ to $100^{\circ}$; $t$-test $\left.\mathrm{p}<0.000\right)$ post-operatively. Supination of the forearm increased from a pre-operative mean of $-12^{\circ}\left(-80^{\circ}\right.$ to $\left.+50^{\circ}\right)$ to a postoperative mean of $36^{\circ}\left(-45^{\circ}\right.$ to $+90^{\circ}$; $t$-test, $\left.\mathrm{p}<0.000\right)$. Arm posture in the resting position was also improved (Fig. 3 ).

Post-operative CT scans were available for three children, and in these the head of the humerus was seen to be relocated within the glenoid fossa (Fig. 4).

\section{Discussion}

Long-standing muscular imbalance around the shoulder leads to progressive glenohumeral dysplasia and instability. Muscle releases and tendon transfers may improve function and arrest the progression of glenohumeral deformity. However, whether they result in substantial glenohumeral remodelling or not remains debatable. ${ }^{8,15}$

Glenohumeral subluxation was found to correlate with scapular elevation and rotation (the SHEAR deformity). The latter consists essentially of abnormal scapular protraction and elevation (Fig. 1a). ${ }^{16}$ This movement deforms the clavicle in a complex manner. The scapular elevation rotates the superior surface of the distal third of the clavicle anteriorly and the lateral migration bends the entire distal third forward. Since the clavicle is fixed at its medial end to 

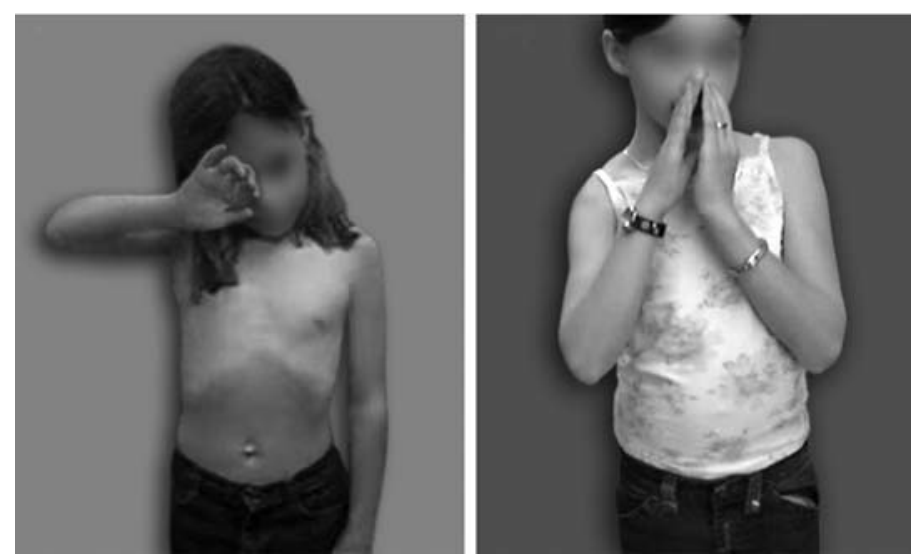

Fig. 3a
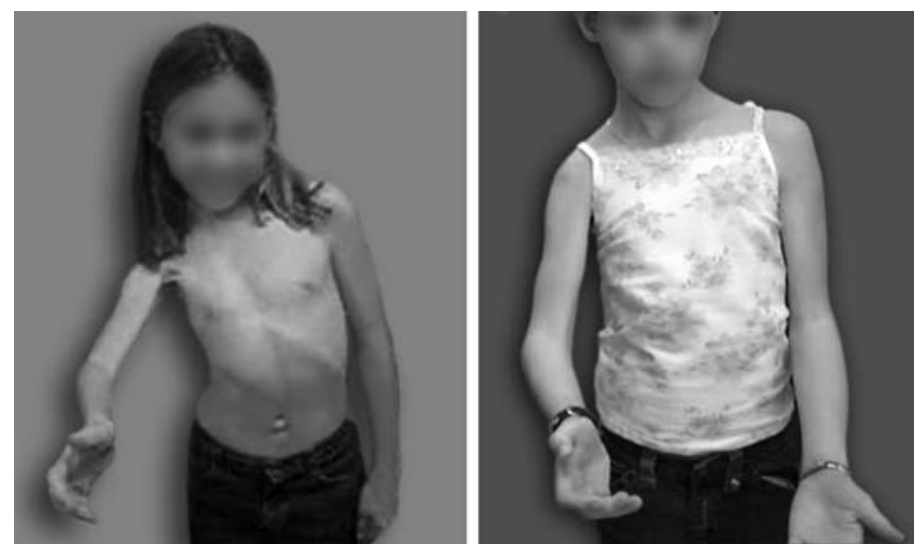

Fig. $3 b$
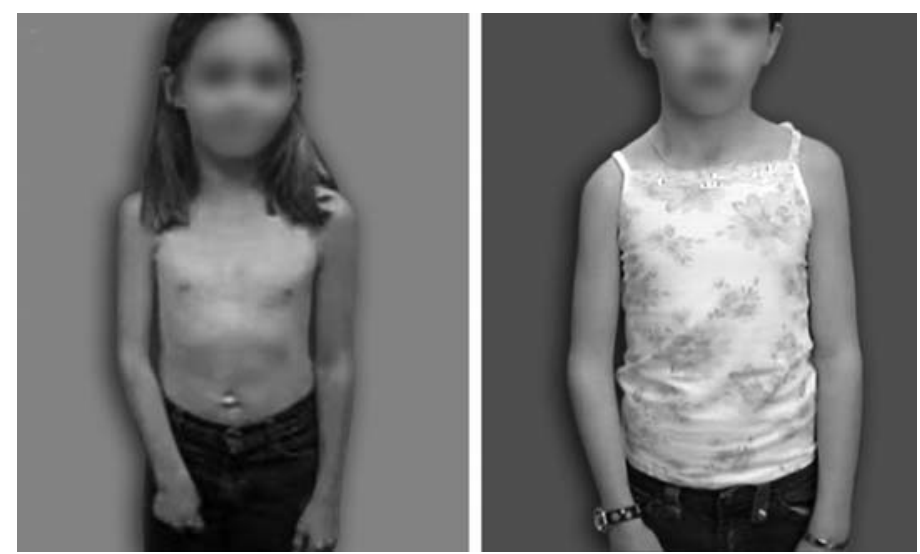

Fig. 3c

Clinical photographs of a nine-year-old girl pre-operatively (left) and 15 months after triangle tilt surgery (right) showing significant improvement in a) hand-tomouth position, b) forearm supination and c) resting arm posture.

the sternum, the body cannot rise superiorly in concert with the scapula through the acromioclavicular ligaments and hence the distal acromioclavicular triangle is tilted superiorly, its anterior surface facing more anteriorly.

The diagnosis of SHEAR deformity can be made clinically but is best defined using 3D CT of the shoulder girdle
(Fig. 1a and 1b). The elevation and forward rotation of the scapula which are evident on 3D CT alters the anatomical plane between the scapular spine and the clavicle by angling this forward (Fig. 1b). The acromioclavicular joint is also tilted anteriorly from its usual level position. The anterior angulation of the joint plane in turn pushes the humeral 

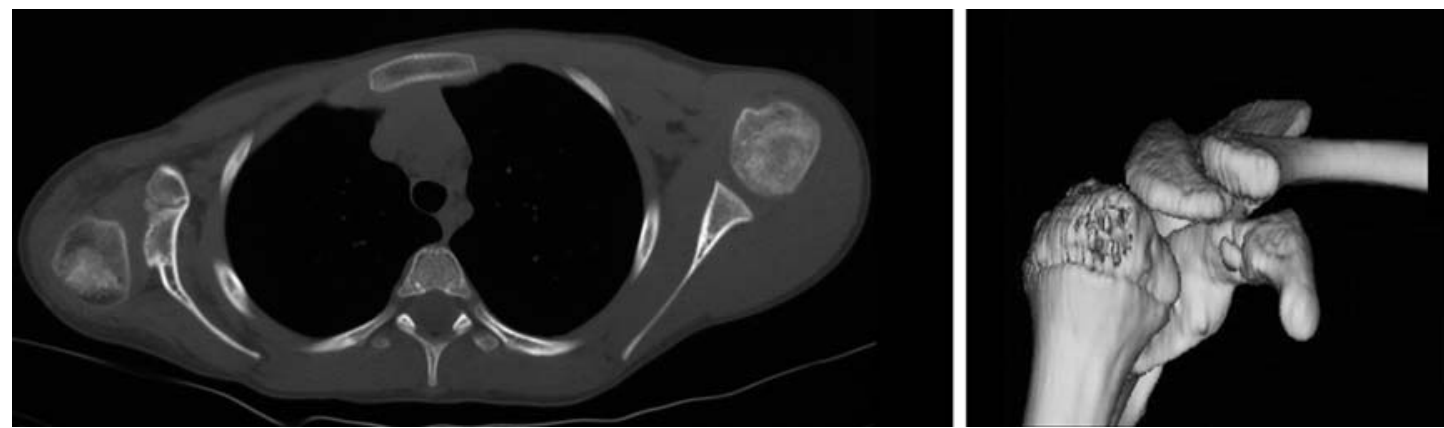

Fig. 4a
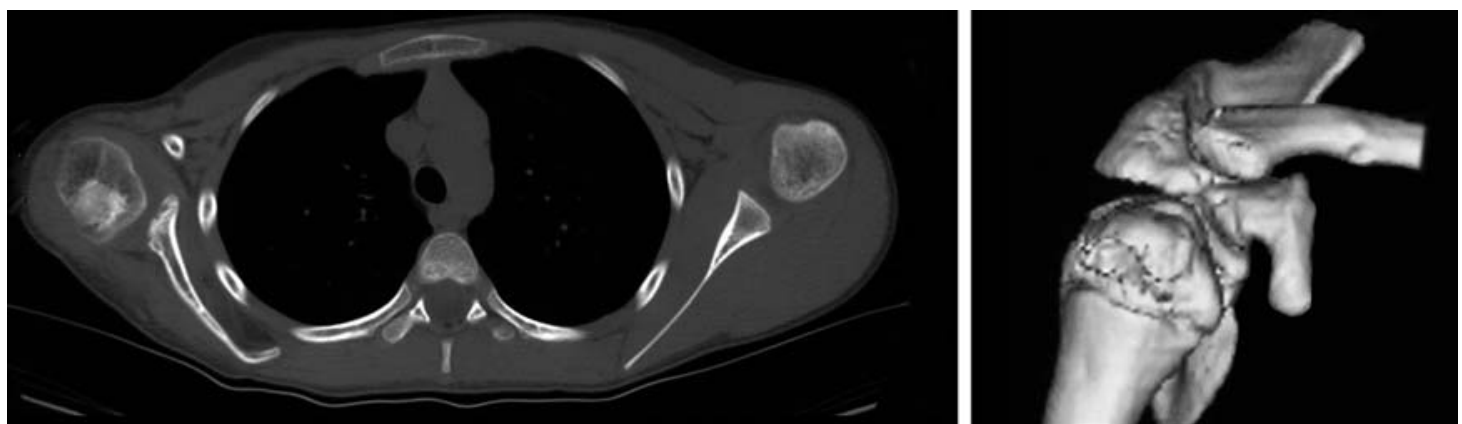

Fig. 4b

Axial (left) and three-dimensional (right) CT views with posterior humeral subluxation a) pre-operatively at the age of nine and b) 18 months after operation showing relocation of the humeral head.

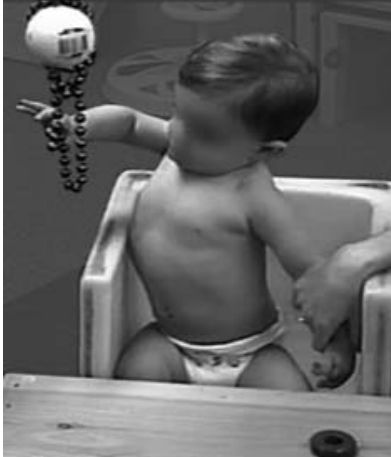

Fig. $5 a$

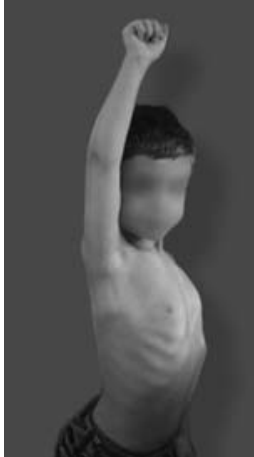

Fig. $5 b$

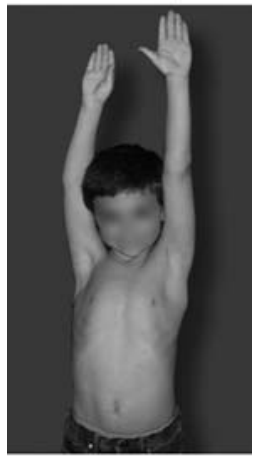

Fig. $5 c$
Clinical photographs of a boy with obstetric brachial plexus injury showing a) limitation of active abduction with typical truncal com pensatory movement at 15 months, b) release of the contracted internal rotators of the shoulder along with decompression and neurolysis of the axillary nerve four years later and c) the result 20 months after the triangle tilt procedure (six years after contracture release). head posteriorly because of the ligamentous connections between the structures.

It is clear that these bony deformities are potentially a source of functional impairment and disability with longterm implications for quality of life. Successful management of these bony changes can reduce the overall morbidity in obstetric brachial plexus injury.

There are conflicting opinions regarding the optimum treatment of residual weakness and functional limitation in this condition. Some surgeons do not perform contracture releases in the presence of an underlying incongruent gleno- humeral articulation because they think that it promotes anterior dislocation and an external rotation and abduction contracture. ${ }^{17-19}$ However, in our experience, neither anterior dislocation nor external rotation and abduction contracture has occurred in any of our patients after contracture release and muscle transfer. ${ }^{20}$ On the contrary, contracture release and muscle transfer greatly improved abduction (Fig. 5 ) and did not alter glenohumeral stability and congruency. The associated medial rotation contracture was not significantly improved by contracture release and muscle transfer, but was treated by the triangle tilt procedure. 

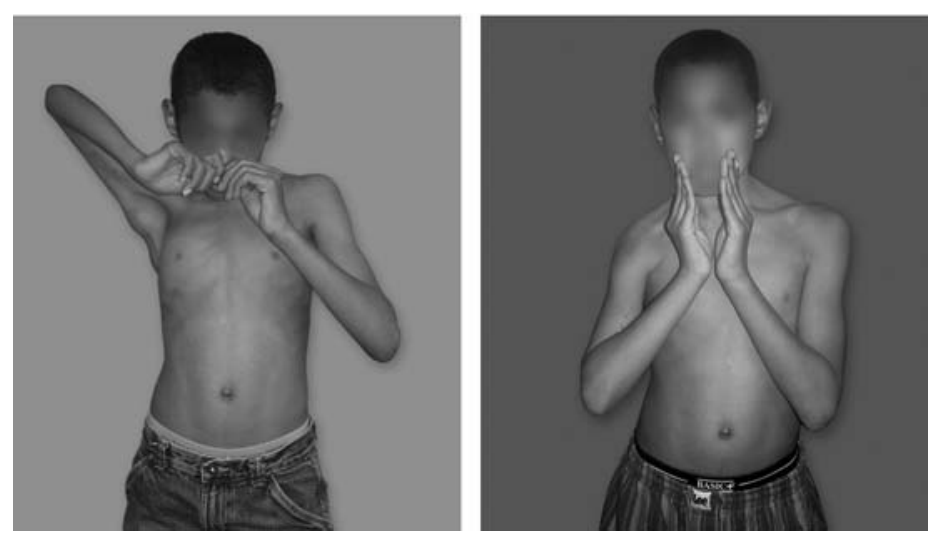

Fig. 6a
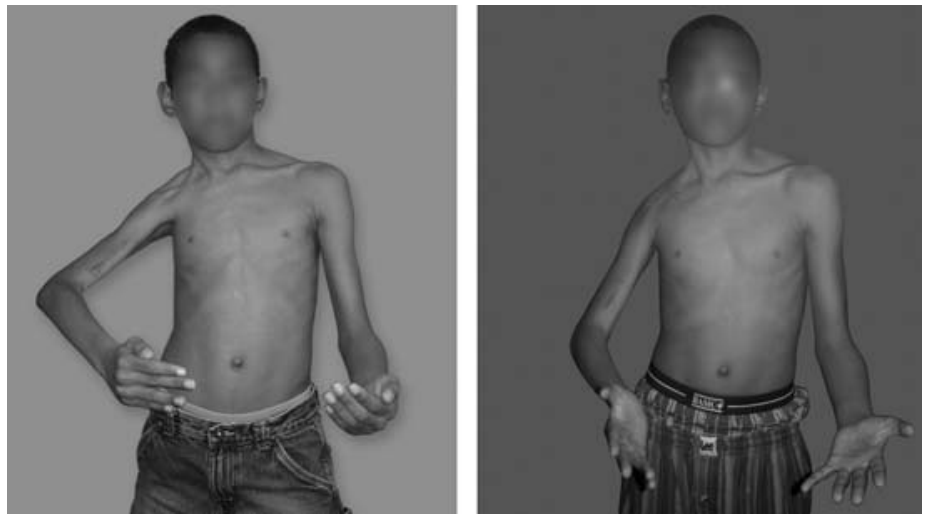

Fig. $6 \mathrm{~b}$
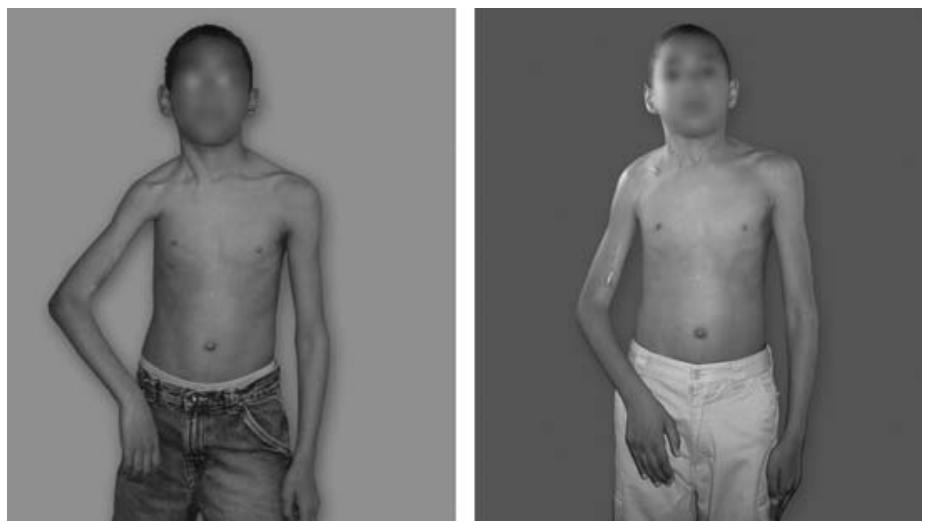

Fig. 6c

Clinical pre- (left) and post-operative (right) photographs of a ten-year-old boy who had previously undergone failed humeral surgery showing a) hand-tomouth movement, b) forearm supination and c) resting position of the arm eight months after triangle tilt surgery.

At present, the most common treatment for medial rotation contracture is humeral osteotomy when the deformity of the glenoid and humeral head is advanced. ${ }^{18,19,21-24}$ However, the procedure does not address the glenohumeral deformity. In two recent patients with severe medial rota- tion contracture who had previously undergone humeral osteotomy with no improvement in function, triangle tilt surgery was performed with marked improvement (Fig. 6). These two patients were not included in the study because the follow-up was less than one year. 
The triangle tilt procedure was designed to eliminate the impingement which occurs in the SHEAR deformity and to improve the position of the humeral head in the glenoid. It is known that progressive glenohumeral dysplasia occurs in children with obstetric brachial plexus injury ${ }^{12,25}$ and is comparable with that observed in the acetabulum in developmental dysplasia of the hip ${ }^{25}$ in which bony procedures to tilt the acetabulum have been used to correct the position of the femoral head in the acetabulum. ${ }^{26,27}$

During surgery, immediately after osteotomy of the clavicle, the distal and proximal clavicular fragments were noted to unwind rapidly, reflecting the abnormal twisting of the clavicle secondary to scapular migration. Moreover, after osteotomy of the acromion process, the distal acromial head and the proximal acromial neck immediately and rapidly separated, with the distal segment moving inferiorly and posteriorly. We believe that these immediate clavicular and acromial movements after osteotomy are evidence of a highly abnormal bony framework around the shoulder, associated with considerable intraosseous torque which is released when the distal acromioclavicular triangle is separated from the abnormal medial structures. The humeral head is related to the lateral structures and therefore moves into a more normal position with the distal acromioclavicular triangle.

The Mallet functional score is the most widely-used and most reliable scoring system for the clinical assessment of shoulder function. ${ }^{27}$ The triangle tilt procedure improved the overall Mallet score by a mean of 4.9 points (1.7 to 8.3). This was largely a result of improved hand-to-mouth position (decreased bugler's sign) and external rotation. Considerable improvement was also seen in hand-to-neck and hand-to-spine movements ( $t$-test, $\mathrm{p}<0.000)$. The Mallet functional score is not sufficiently sensitive to discriminate subtle differences in all patients, and therefore additional measurements of the hand-to-mouth and supination angles were made. These both showed significant improvement after triangle tilt surgery.

The pre-operative medial rotation caused the arm to flare laterally in the resting position with the elbow in flexion. The surgical levelling of the acromioclavicular triangle moved the glenohumeral axis towards neutral and significantly improved the arm position and movement (Fig. 3).

The triangle tilt operation restores the glenohumeral functional unit to a more natural position. Correction of the internal rotation deformity is thus achieved. The posterior glenohumeral capsulodesis resolves the posterior laxity caused by displacement of the humeral head.

\section{Supplementary Material}

\section{ё} A supplementary table showing the functional assessment and radiological classification of the patients is available with the electronic version of this article on our website at www.jbjs.org.uk

No benefits in any form have been received or will be received from a commercial party related directly or indirectly to the subject of this article.

\section{References}

1. Kay SP. Obstetrical brachial palsy. Br J Plast Surg 1998;51:43-50.

2. Gilbert A, Tassin JL. Surgical repair of the brachial plexus in obstetric paralysis. Chirurgie 1984;110:70-5 (in French).

3. Waters PM. Update on management of pediatric brachial plexus palsy. J Pediatr Orthop B 2005;14:233-44.

4. Birch R, Bonney G, Wynn Parry CB. Birth lesions of the brachial plexus. In: Birch R, Bonney G, Wynn Parry CB, eds. Surgical disorders of the peripheral nerves. New York: Churchill Livingstone, 1998:209-33.

5. Moukoko D, Ezaki M, Wilkes D, Carter P. Posterior shoulder dislocation in infants with neonatal brachial plexus palsy. J Bone Joint Surg [Am] 2004;86-A:787-93.

6. Hoffer MM, Phipps GJ. Closed reduction and tendon transfer for treatment of dislocation of the glenohumeral joint secondary to brachial plexus birth palsy. J Bone Joint Surg [Am] 1998;80-A:997-1001.

7. Safoury Y. Muscle transfer for shoulder reconstruction in obstetrical brachial plexus lesions. Handchir Mikrochir Plast Chir 2005;37:332-6.

8. Waters PM, Bae DS. Effect of tendon transfers and extra-articular soft-tissue balancing on glenohumeral development in brachial plexus birth palsy. J Bone Joint Surg [Am] 2005;87-A:320-5.

9. Adelson PD, Nystrom NA, Sclabassi R. Entrapment neuropathy contributing to dysfunction after birth brachial plexus injuries. J Pediatr Orthop 2005;25:592-7.

10. Kambhampati SB, Birch R, Cobiella C, Chen L. Posterior subluxation and dislocation of the shoulder in obstetric brachial plexus palsy. $J$ Bone Joint Surg $[B r]$ 2006;88-B:213-19.

11. Mallet J. Obstetrical paralysis of the brachial plexus. II: Therapeutics: treatment of sequelae: priority for the treatment of the shoulder: method for the expression of results. Rev Chir Orthop Reparatrice Appar Mot 1972;58(Suppl 1):166-8 (in French).

12. Waters PM, Smith GR, Jaramillo D. Glenohumeral deformity secondary to brachial plexus birth palsy. J Bone Joint Surg [Am] 1998;80-A:668-77.

13. Nath RK, Paizi M. Scapular deformity in obstetric brachial plexus palsy: a new finding. Surg Radiol Anat 2007;29:133-40.

14. Friedman RJ, Hawthorne KB, Genez BM. The use of computerized tomography in the measurement of glenoid version. J Bone Joint Surg [Am] 1992;74-A:1032-7.

15. Pearl ML, Edgerton BW, Kazimiroff PA, Burchette RJ, Wong K. Arthroscopic release and latissimus dorsi transfer for shoulder internal rotation contractures and glenohumeral deformity secondary to brachial plexus birth palsy. J Bone Joint Surg [Am] 2006;88-A:564-74.

16. Zancolli EA. Classification and management of the shoulder in birth palsy. Orthop Clin North Am 1981;12:433-57.

17. Kirkos JM, Papadopoulos IA. Late treatment of brachial plexus palsy secondary to birth injuries: rotational osteotomy of the proximal part of the humerus. J Bone Joint Surg [Am] 1998;80-A:1477-83.

18. Al-Qattan MM. Rotation osteotomy of the humerus for Erb's palsy in children with humeral head deformity. J Hand Surg [Am] 2002;27:479-83.

19. Nath RK, Paizi M. Improvement in abduction of the shoulder after reconstructive soft-tissue procedures in obstetric brachial plexus palsy. J Bone Joint Surg [Br] 2007;89-B:620-6.

20. Egloff DV, Raffoul W, Bonnard C, Stalder J. Palliative surgical procedures to restore shoulder function in obstetric brachial palsy: critical analysis of Narakas' series. Hand Clin 1995;11:597-606.

21. Waters PM, Bae DS. The effect of derotational humeral osteotomy on global shoulder function in brachial plexus birth palsy. J Bone Joint Surg [Am]2006;88-A:1035-42.

22. Faysse R. Obstetrical paralysis of the brachial plexus. II: therapeutics: treatment of sequelae: d: humeral derotation osteotomy in the sequelae. Rev Chir Orthop Reparatrice Appar Mot 1972;58(Suppl 1):187-92 (in French).

23. Akinci M, Ay S, Kamiloglu S, Ercetin $\mathbf{0}$. External rotation osteotomy of the humerus for the treatment of shoulder problems secondary to obstetric brachial plexus palsy. Acta Orthop Traumatol Turc 2005;39:328-33 (in Turkish).

24. Pearl ML, Edgerton BW. Glenoid deformity secondary to brachial plexus birth palsy. $J$ Bone Joint Surg [Am] 1998;80-A:659-67.

25. Hartofilakidis G, Stamos K, Karachalios T, Ionnidis TT, Zacharakis N. Congenital hip disease in adults: classification of acetabular deficiencies and operative treatment with acetabuloplasty combined with total hip arthroplasty. J Bone Joint Surg [Am] 1996; 78-A:683-92.

26. Lalonde FD, Frick SL, Wenger DR. Surgical correction of residual hip dysplasia in two pediatric age-groups. J Bone Joint Surg [Am] 2002;84-A:1148-56.

27. Bae DS, Waters PM, Zurakowski D. Reliability of three classification systems measuring active motion in brachial plexus birth palsy. $J$ Bone Joint Surg $[\mathrm{Am}]$ 2003;85-A:1733-8 